\title{
El arqueólogo como hispanista. 150 años de investigación arqueológica alemana en España
}

\section{The archaelogist as hispanist. 150 years of German archaelogical research in Spain}

\author{
Thomas ScHATTNER \\ Instituto Arqueológico Alemán \\ thomas.schattner@dainst.de
}

Fecha de recepción: 15-11-2019

Fecha de aceptación: 03-03-2020

\section{RESUMEN}

Desde una perspectiva histórica se analizan en tres apartados las distintas y variadas aportaciones de la intelectualidad alemana a la Cultura y especialmente al estudio de las Antigüedades hispánicas. Son sobre todo arqueólogos, prehistoriadores, historiadores, epigrafistas, pero también filólogos, historiadores de arte y otros tantos más. Les une su interés por los problemas científicos, pero además, desarrollaron y desarrollan hasta el día de hoy un especial interés que se extiende hacia el país y su gente y que los convirtió, de esta manera, en hispanistas.

PALABRAS CLAVE: Historiografía, Hispanismo, Arqueología

Topónimo: Alemania

Período: Antigüedad

\section{ABSTRACT}

From a historical perspective, the diverse contributions of German scholars to the culture and in particular to the study of Hispanic Antiquities is analyzed in three sections. These are mainly archaeologists, prehistorians, historians and epigraphers, but also philologists, art historians and many others. They are united by their interest in scientific problems, but also developed and continue to develop a special interest in the country and its people, thus becoming genuine Hispanists.

Key words: Historiography, Hispanism, Archæology

Place names: Germany

Period: Antiquity 


\section{INTRODUCCIÓN}

Una de las peculiaridades del desarrollo cultural y lingüístico es que los conceptos de los -ismos específicos de cada país han tomado caminos y direcciones muy diferentes ${ }^{1}$. El portuguesismo, el galicismo o el germanismo — como en muchas otras lenguas - denotan palabras prestadas de estas lenguas que se utilizan en otra. Sin embargo, el americanismo es conocido menos como un movimiento de la Iglesia Católica del siglo XIX que en su antítesis como antiamericanismo. La atribución semántica de estos términos puede ser neutral como en el caso del portuguesismo, el galicismo, el germanismo o negativa como en el del antiamericanismo. En este contexto, el término hispanismo tiene un efecto refrescante. Porque contiene principalmente no sólo la función de la palabra de préstamo descrita, sino también —quizás más claramente que en los otros idiomas mencionados— la preocupación general por los temas de la cultura y el lenguaje hispánicos. En este sentido, tiene una connotación positiva y ocupa una suerte de posición especial, que sin duda se deriva de su extensión en términos de contenido a América Latina, sobre todo porque también incluye las peculiaridades de las respectivas derivaciones dialectales y las culturas de los países hispanos de ese continente.

A continuación, intentaremos dibujar un panorama de los arqueólogos alemanes del pasado como hispanistas, una cualidad que todos poseían de una u otra manera, ya que todos ellos, cada uno a su manera, no solo abordaban las cuestiones científicas específicas que les preocupaban, sino que extendían su trabajo mucho más allá, instruyendo en universidades, museos o academias españolas, ocupando puestos o practicando la investigación en grupos. A este compromiso institucional hay que sumar su interés por el país y su gente, que los convirtió en hispanistas en el sentido más estricto de la palabra, ya que en este punto se añade un elemento emocional que puede sentir todo aquel que haya comido tapas en una plaza española al final de una tarde, que haya experimentado interludios espontáneos de danza en una feria, que haya visto las lágrimas en los ojos durante una procesión, o que simplemente haya absorbido la grandeza del paisaje español al anochecer. Antes, sin embargo, describiremos en dos secciones primero los antecedentes (II), luego el marco institucional del trabajo de investigación (III), y, finalmente, a título de conclusión, una sección referida al arqueólogo como hispanista (IV).

\section{ANTECEDENTES}

Las conexiones más estrechas de los países germánicos con España y por lo tanto el interés general por este subcontinente de Europa Occidental aumentaron en el siglo XIX. Los vínculos institucionales se iniciaron seriamente durante esa época, la imagen de España se iluminó. Hasta entonces y durante mucho tiempo, esta había sido marcada por la "leyenda negra". El debate sobre el fenómeno ya había tenido lugar en Alemania un siglo antes que en la propia España. Carlo Denina, que huyó a la Berlín protestante en 1784, replicó a la provocativa pregunta de Nicolas Masson de Morvilliers: "¿Que doit-on à l'Espagne?" en un brillante discurso, en el que señalaba los méritos científicos y culturales de España².

En esa época hay que mencionar al pintor alemán Anton Raphael Mengs (1728-1779), uno de los principales pintores del neoclasicismo en España. También hay que destacar

1 Estudios sobre la temática presentada en este artículo son muchos y variados y han sido tratados de forma diversa, véanse por ejemplo las contribuciones más recientes como son las de Raders y Schilling, 1995; Renner y Siguán, 1999; Rodiek, 2000; Salas y Briesemeister; 2000, Vega y Wegener, 2002; Bader y Olmos, 2004; Briesemeister, 2004 citados en la bibliografía. Al tener este artículo un carácter genérico, se prescinde de citas concretas y al lector se remite a la bibliografía en anejo al final de cada párrafo.

2 Maier y Schattner, 2010; Maier y Schattner, 2013; Marzoli, Maier y Schattner, 2014. 
a Karl Christian Friedrich Krause (1781-1832), que jugó un papel relevante en la filosofía del siglo XIX y fue particularmente popular en España. Entre las universidades, Göttingen fue la sede de los hispanistas alemanes. La institución compró sistemáticamente libros españoles desde mediados del siglo XVIII. No es de extrañar, por tanto, que la primera historia de la literatura española escrita por un alemán apareciera allí en 1829: Friedrich Bouterwek, "Geschichte der spanischen Poesie und Beredsamkeit" (1804). Thomas Christian Tychsen escribió una contribución sobre literatura española para la versión alemana de la obra francesa de Jean-François Bourgoing, "Neue Reise durch Spanien" (1789-1800). Este, posteriormente viajó con el teólogo danés Daniel Gotthilf Moldenhawer a España para elaborar el catálogo de manuscritos griegos del Escorial junto con Francisco Pérez Bayer. Georg Christian Gebauer escribió una historia de España que permanecería inédita. Pero también hubo notables impulsos desde el Weimar de Goethe. Allí se publicó la revista "Magazin der spanischen und portugiesischen Literatur" con una tirada de 1.500 ejemplares. El creciente interés por la lengua española dio lugar a un primer diccionario (1795-1805) escrito por Ernst August Schmid. En la vecina Universidad de Jena enseñaban los hermanos Schlegel, Schiller, Hegel y Fichte, así como el ya mencionado Krause. Johann Gottfried Herder (1744-1844), entonces superintendente protestante de Weimar, destacó la Edad Media española con la figura del Cid en sus estudios folclóricos y tuvo así una influencia decisiva en la imagen de España. Su teoría del espíritu popular y su concepción de la nación suscitaron el entusiasmo por el modelo español y su literatura nacional. La mezcla de estos diferentes elementos ibéricos, romanos y árabes y su unión en una amalgama cristiano-islámica hacen de España el país romántico por excelencia, lo que se opone a la concepción clasicista. La imagen de España sigue marcada por los caballeros, por un lado, y los moros, por otro, que se complementan entre sí. A los árabes se les llama portadores de luz de la cultura europea y a los españoles se les considera como "árabes ennoblecidos". En la arquitectura romántica de la época se inicia una corriente que coloca el estilo mudéjar, considerado como el epítome de la arquitectura islámica ${ }^{3}$, como modelo a seguir ${ }^{4}$. Mientras que Herder centró su atención en la España islámica, Friedrich Schlegel (1772-1829) se centró en los visigodos.

Destacó su herencia germánica y reconoció en ella la referencia de la España medieval a la tradición más antigua. Por esta vía surgieron toda una serie de estudios históricos y jurídicos de la España medieval, como la "Geschichte der Westgoten/Historia de los visigodos" de Joseph von Aschbach (1827). Asimismo hay que mencionar las obras de Friedrich Wilhelm Lembke, "Die Zeiten von der vollständigen Eroberung durch die Römer bis gegen die Mitte des neunten Jahrhunderts/Los tiempos desde la conquista completa por los romanos hasta mediados del siglo IX" (1831); Heinrich Schäfer, "Von den ersten Jahrzehnten des neunten Jahrhunderts bis zum Anfang des zwölften/Desde las primeras décadas del siglo IX hasta principios del XII" (1844); Friedrich Wilhelm Schubert, "Geschichte des südöstlichen Spaniens, insbesondere seiner inneren Zustände im Mittelalter/Historia del sudeste de España, en particular sus condiciones interiores en la Edad Media" (1861) y, finalmente, Friedrich Wilhelm Schirrmacher (1824-1904), profesor en Rostock, con tres volúmenes "Geschichte von Spanien/Historia de España" (1890-1902), que abarca desde el siglo XII hasta 1516. Al mismo tiempo, se publican obras de referencia contemporánea como la de Herrmann Baumgarten, "Geschichte Spaniens vom Ausbruch der Französischen Revolution bis auf unsere Tage/Historia de España desde el estallido de la Revolución

3 Giese y Varela, 2016.

4 En España, por ejemplo, el Palacio de Orleáns y Borbón en Sanlúcar de Barrameda; otros ejemplos documentados en Suiza han sido reunidos en el volumen de Giese, el-Wakil y Varela, 2019. 
Francesa hasta nuestros días" (1865-1871). La ya mencionada "leyenda negra" contrasta con una nueva imagen de España, que pasa a ser considerada la tierra mágica para la regeneración alemana. Como hogar del romanticismo sirve como una especie de manantial de agua fresca y de salud ${ }^{5}$.

Si bien las anteriores líneas de comunicación se caracterizaban por una conexión distante, en el sentido de que los participantes en el discurso generalmente habían llegado a conocer y amar a España no por su propia experiencia, sino por el conocimiento adquirido a través de los libros, esto cambió gradualmente a lo largo del siglo XIX a través del considerable aumento de los contactos personales, es decir, a través de colonos, soldados y viajeros, y con ello a través de los documentos correspondientes como pueden ser archivos administrativos, noticias de periódicos, relatos de testigos oculares y también a través del lenguaje de la pintura.

La presencia masiva de colonos procedentes de Alemania jugó un papel importante para el contacto personal. En 1770 la antigua idea de una colonización de las mesetas y del interior de España, que había estado presente durante toda la historia regional y agrícola española desde la Reconquista, fue puesta en práctica. Al igual que Prusia 0 Rusia, España también desarrolló un programa para el asentamiento de colonos en zonas despobladas. La idea formaba parte del espíritu de la llustración. Los colonos se dedicarían a la agricultura, la artesanía y la ganadería, los niños debían ser enviados a la escuela y de esta manera no sólo se beneficiaría la economía, sino también el Estado. En nombre de Carlos III, el bávaro Johann Kaspar von Thürriegel puso en marcha la orden real en abril de 1767. Reclutó colonos principalmente en el suroeste de Alemania, Alsacia y Suiza, y las zonas se convirtieron en países de emigración clásicos durante este período. En 1770 más de 7.000 colonos ya habían emigrado y se habían asentado tanto en Sierra Morena como en el valle del Guadalquivir ${ }^{6}$.

También la participación de las tropas de la Confederación del Rin (Rheinbund) en la Guerra de la Independencia (1807-1814) se encuadran en este fenómeno. Estos (más de 15.000 efectivos) procedían de Baden, Nassau y Hessen, así como del Gran Ducado de Berg, de Westfalia y de Würzburg. Los informes de los soldados ${ }^{7}$, junto con la aparición de la prensa, tuvieron a menudo un impacto positivo, añadiendo una nueva faceta al interés por España. La resistencia española contra Napoléon se equipara poética y literalmente a la que se opuso a la invasión romana. Es el caso de Ernst Moritz Arndt, que tematiza el asedio de Sagunto en 1811 exagerando patéticamente el nacionalismo, llamando a los Celtíberos y Astures señores heroicos (Heldenherren). Esta atención hacia la capacidad bélica de España y de los españoles, de su literatura e historia, lleva a la introducción en el vocabulario alemán de palabras como guerrilla, liberalismo y camarilla como palabras extranjeras, hispanismos, que se incorporarán al uso lingüístico de los políticos alemanes ${ }^{8}$.

Desde la segunda mitad del siglo XVIII, la literatura de viajes ha desempeñado un papel cada vez más importante en Europa. Esto hizo que España se convirtiera en un lugar europeo de anhelo junto a Italia. Mientras que en Italia el interés se centra en las obras de arte y los monumentos de todas las épocas combinados con el estilo de vida italiano, más ligero, en España predomina el contraste entre la oscura Edad Media, la elegancia islámica y la severidad religiosa de la vida. A España, junto con Alemania, se le considera el país romántico por excelencia9.

5 Maier y Schattner, 2013.

6 Briesemeister, 2004.

7 Ibídem; Maier y Schattner, 2013.

8 Ibídem.

9 Karge y Fritz, 2007; Maier y Schattner, 2013. 
La combinación de una mala infraestructura de carreteras y conexiones de transporte, y las inciertas condiciones políticas imperantes tras el fin de la Guerra de la Independencia, hizo que España fuera inicialmente atractiva solo para los aventureros. En el contexto del panorama descrito anteriormente, marcado por el romanticismo, se desarrolló, sin embargo, un atractivo especial que España, en particular el Al-Andalus islámico, ejerció sobre el público educativo europeo. La atención se centró en Granada con la Alhambra y Sevilla con la pintura del siglo XVII de Murillo en particular ${ }^{10}$.

Además de la traducción de obras en inglés o francés como el "Voyage pittoresque et historique de l'Espagne" de Alexandre de Laborde (1806) o el "Viage por España" de Antonio Ponz (1775-1779) también hay un aumento en la producción de otras fuentes europeas escandinavas, pero también de alemanas. Estos, estimulan cada vez más el interés por los monumentos del país y dibujan un cuadro que estiliza Andalucía en general y la Alhambra de Granada en particular, convertidos en un lugar de anhelo no solamente para los alemanes sino para los europeos en general. Más o menos al mismo tiempo aparecen las obras de Alphonse-René de Chateaubriand "Les aventures du dernier Abencerrage" (1826) y la colección novelística de Washington Irving "The Alhambra" (1832). Chateaubriand estuvo en 1807 en Granada y allí conoció a Natalie, la hermana de Laborde, con quien tuvo una aventura amorosa que obviamente lo inspiró al escribir la obra mencionada. De hecho, el encanto de España se desarrolló no sólo a partir de su literatura y sus monumentos, sino también de su luz radiante, su exuberante vegetación, sus coloridas fiestas, sus procesiones, sus corridas de toros y sus insinuantes tentaciones eróticas encarnadas en el drama "Don Juan Tenorio" de José de Zorrilla y la ópera "Carmen" de Georges Bizet. En casi todas las obras artísticas la mujer andaluza aparece con su vestimenta enfáticamente femenina, sus ojos negros y su animado juego de abanicos, que cautivó a propios y extraños.

A partir de este momento, hacia 1830, se puede observar el descubrimiento de Andalucía. Este se produce, no solo a través de sus figuras literarias y de sus pintores con sus cuadros, sino también a través de las primeras investigaciones científicas a mayor escala y de mayor alcance ${ }^{11}$. Entre los pintores alemanes como Wilhelm Gail, Eduard Gerhardt, Adolf Seel y Fritz Bamberg, las representaciones de la Alhambra son el motivo preferido y, por tanto, un género por derecho propio. Este colorido cuadro artístico presentado por los extranjeros, especialmente de Andalucía, marca un fuerte contraste con las observaciones llevadas a cabo por los mismos españoles en la época anterior. Ponz, por ejemplo, no encuentra ningún aprecio particular por Andalucía en la obra antes mencionada; al ser clasicista, su elogio se dirige hacia el clasicismo del siglo XVI.

Como resultado de la literatura de viajes internacionales, surgió en España la tendencia literaria conocida como costumbrismo, que recurrió a las costumbres de las distintas regiones entre las que Andalucía desempeñó un papel esencial. Sin embargo, hay que tener en cuenta que la visión de Andalucía como la encarnación de España y su esencia se remonta, en última instancia, a enfoques que fueron abordados desde el extranjero ${ }^{12}$.

Además, se producen los primeros viajes de carácter científico, como el de Wilhelm von Humboldt al País Vasco entre 1799 y 1801, que dio lugar a la investigación lingüística sobre el euskera ${ }^{13}$ y estableció la disciplina académica de la vascología. Estos estudios fueron continuados más tarde por Hugo Schuchhardt en Graz (Austria). Su hermano

10 Ibídem, 2007.

11 Por ejemplo las primeras investigaciones sobre el arte andalusí de Ludwig Schorn (1831).

12 Karge y Fritz, 2007.

13 Prüfung der Untersuchungen über die Urbewohner Hispaniens vermittelst der vaskischen Sprache (1821). 
Alejandro recibió el permiso de Carlos IV para realizar un viaje geodésico por España y escalar el Pico del Teide (3.718 m.) en las Islas Canarias como preparación para sus expediciones a Sudamérica. Ya en 1797 el botánico Heinrich Friedrich Link había viajado por Portugal y España acompañado por Johann Centurius von Hoffmannsegg. Todas estas investigaciones dieron lugar a las publicaciones correspondientes, lo que permitió la difusión de las mismas ${ }^{14}$.

El redescubrimiento del Siglo de Oro español (ca. mediados del siglo XVI-mediados del XVII) por parte de los románticos alemanes en un principio y de los representantes del clasicismo de Weimar posteriormente, desencadenó una euforia hacia España y los españoles, especialmente en los países alemanes, pero también en los demás países europeos. A mediados del siglo XIX en Europa, y especialmente en Baviera, una bailarina que se hiciera pasar por española llamaba fácilmente la atención. No hay otra explicación para el episodio de Lola Montez. La irlandesa Elizabeth Rosanna Gilbert (1821-1861) había adoptado el apodo como su nombre artístico. Sin embargo, su dominio de la lengua española era aún inferior al del rey Ludwig I de Baviera. Su aventura con la bailarina le costó el trono en $1848^{15}$.

La obra "Geschichte der dramatischen Literatur und Kunst in Spanien/ Historia de la literatura dramática y del arte en España" (1845/46), de Adolf Friedrich von Schack marcó un hito en la investigación alemana sobre España, porque el estudio polariza las tendencias de ese momento y las lleva a su punto de ebullición. Schack consideró que España era uno "de los pueblos más nobles del mundo", por lo que su teatro era de "sublime perfección". Según este autor, el arte, la literatura y el teatro nacen de conceptos como el gusto y el espíritu nacional y, por lo tanto, de la propia alma de esta nación, y son, en el mejor sentido del romanticismo, productos genuinos de la historia nacional y de sus leyendas heroicas.

Sin embargo, a diferencia de Francia, donde los "Études hispaniques" como tales habían ocupado un lugar permanente en las universidades desde finales del siglo XIX $y$, al final, lo encontraron en la Universidad de Burdeos, en Alemania la euforia descrita anteriormente no llevó al establecimiento de la asignatura en la Universidad Reformada de Wilhelm von Humboldt. Hasta el día de hoy, las lenguas románicas en las universidades alemanas están integradas en los departamentos de filología de manera uniforme bajo esa misma designación.

Por parte española, la Institución Libre de Enseñanza (1876-1936) se convirtió en una institución no gubernamental independiente de primera importancia para el desarrollo educativo, científico y social de España en el período comprendido entre Restauración, Regeneracionismo y Guerra Civil. Para su fundador, Francisco Giner de los Ríos, la Alemania intelectual fue un modelo por la reforma universitaria de Humboldt y los logros de los científicos alemanes. Fue influenciado por la filosofía de Krause así como por la pedagogía de Johann Heinrich Pestalozzi (1746-1827). La primera "Historia general de Alemania" en tres volúmenes de Vicente Ortiz de la Puebla (1877) responde a este interés español en Alemania, al igual que el "Ensayo sobre el movimiento intelectual en Alemania" de José del Perojo y Figueras (1875), traductor de "La crítica de la razón pura" de Kant. Como resultado de la Institución Libre de Enseñanza, se establecieron otras fundaciones institucionales, incluyendo la Residencia de Estudiantes y la Junta de Ampliación de Estudios e Investigaciones Científicas (1907). Antes de la Primera Guerra Mundial, casi la mitad de

14 Maier y Schattner, 2013.

15 Tietz, 1989; Raders y Schilling, 1995; Renner y Siguán, 1999; Rodiek, 2000; Geisler, 2001; Vega y Wegener, 2002; Bader y Olmos, 2004; Hellwig, 2007. 
los becarios fueron a Alemania ${ }^{16}$. Este fue el resultado de la muy bien recibida investigación alemana en España en casi todas las materias, tales como Derecho y Filosofía del Derecho, Política y Economía, Educación y Psicología, Medicina, Ciencias Naturales e Ingeniería.

Como resultado de la Primera Guerra Mundial, la promoción de la política cultural exterior fue cobrando protagonismo en Europa. Primero Francia y luego Alemania crearon institutos de investigación. Ejemplo de ello son la Escuela de Altos Estudios Hispánicos, más tarde Casa de Velázquez, creada por la Universidad de Burdeos en 1909, y la KaiserWilhelm Gesellschaft zur Förderung der Wissenschaften/Sociedad Kaiser Wilhelm para el Avance de la Ciencia, que, sin embargo, sólo contó con una pequeña representación llamada "punto de trabajo" desde 1911. El spiritus rector fue Paul Fridolin Kehr, ex director del Deutsches Historisches Institut/Instituto Histórico Alemán de Roma, en asociación con el profesor de historia de Friburgo, Heinrich Finke. Ambos habían tratado científicamente temas españoles, en particular la historia de Aragón, y Finke había dirigido a más de 30 estudiantes de doctorado españoles. En 1924/25, la institución fue incorporada al "Centro de Intercambio Intelectual Germano-Español”, que publicó la revista “Investigación y Progreso", basada en la revista "Forschung und Fortschritt" de Baden-Württemberg. Sus tareas incluían la creación de un intercambio de noticias científicas en beneficio de españoles y alemanes, la concesión de pequeñas becas para viajes de estudio, la creación de una biblioteca y la correspondiente bibliografía germano-española, conferencias y cursos de alemán, así como la creación de un sistema de préstamos internacionales para libros y escritos.

En la España de entreguerras, la disputa sobre la influencia de las respectivas lenguas es muy evidente ${ }^{17}$. En ello, el bando alemán favorece el español como lingua franca a expensas del francés, ya que, según el romanista muniqués Karl Vossler (1872-1949), encarna valores eternos que parecían adecuados para iniciar una renovación moral tras el trauma de la guerra. Vossler, de convicción republicano-democrática y sin embargo el tipo de estudioso apolítico, evoca así cualidades y virtudes que ya se le habían atribuido a España en el Romanticismo, a saber, el carácter arcaico que va más allá de lo profano. En su ensayo sobre el significado europeo de la cultura española, escribe:

El español, que es en la lucha de las armas el guerrero nato, el guerrillero, viene a ser en la lucha del espíritu un militarista organizador y ordenancista, el antípoda, y por ello precisamente el complemento idóneo del soldado prusiano, lo mismo que lo es del polemista filósofo y del crítico intelectual de los pueblos germánicos y del mundo protestante ${ }^{18}$.

Estas afirmaciones son tanto más importantes cuanto que el rival de Vossler, Ernst Robert Curtius (1886-1956), llega a una conclusión similar. Curtius observa la "expansión espiritual de España", que tiene como un "país excéntrico", que "acaba de entrar en el círculo de las potencias espirituales (geistige Großmächte) y se ha puesto de moda precisamente a causa de su sistema de valores espirituales (geistiges Wertesystem)"19.

En resumen, hasta mediados del siglo XIX, la influencia de España en Alemania fue mayor, y luego se invirtió la relación. Lo que ambos países tienen en común es que fueron idealizados y tomados como modelos a seguir en diferentes épocas, el Romanticismo y el período Wilhelminiano. Sin embargo, en el período de entreguerras se preparó el terreno para la instalación de institutos científicos.

16 Sobre éstas véase, p. ej., Díaz Andreu, 1995.

17 Hera Martínez, 2002.

18 Vossler, 1944.

19 Briesemeister, 2004; Maier y Schattner, 2013. 


\section{INSTITUCIONES CIENTÍFICAS ALEMANAS DE HUMANIDADES EN ESPAÑA}

La idea de establecer un departamento del Instituto Arqueológico Alemán (en adelante IAA) en España se hizo pública por primera vez en las celebraciones de su centenario. El entonces Presidente Gerhard Rodenwaldt había invitado a una delegación española compuesta por José Ramón Mélida y Pedro Bosch Gimpera. La idea coincidió con una fase de expansión del IAA, ya que el departamento de El Cairo se había incorporado en 1907 y el departamento de Estambul en 1929, el año de la crisis económica mundial. La idea fue jalonada científicamente a través de la traducción de la obra de Rodenwaldt "Kunst der Antike/ Arte clásico" (1931), a la que Mélida añadió una introducción sobre el arte clásico en España. Al mismo tiempo, Julio Martínez Santa-Olalla era lector en Bonn y Antonio García y Bellido y Martín Almagro Basch eran becarios en Alemania. Por parte alemana, Georg Leisner, Hans Zeiß y Helmut Schlunk trabajaron sobre temas españoles, lo que dio lugar a numerosos viajes. En 1932 Theodor Wiegand siguió a Rodenwaldt. El nuevo presidente, de avanzada edad ya en ese momento, no reanudó inmediatamente el plan de establecer un departamento en España. La razón se puede ver en la dedicación exclusivamente científica del IAA, un hecho, que lo hizo parecer inadecuado como portador para la política cultural exterior. Mientras tanto, el "Centro de Intercambio Intelectual Germano-Español" continuó su labor, pero en 1934 fue reestructurado en una rama del "Deutscher Akademischer Austauschdienst/Servicio Alemán de Intercambio Académico" y reorientado políticamente en esa ocasión. Si hasta entonces el trabajo se había enfocado exclusivamente a criterios científicos, ahora los objetivos políticos fueron ocupando un lugar cada vez más importante. Sin embargo, el Centro mostró una cierta inercia institucional, que luego se expresó en la revista "Investigación y Progreso", en el sentido de que el número de autores españoles y portugueses aumentó significativamente en ese momento. En 1941 se produjo una nueva reestructuración, que equivalió a una disolución, aunque la revista continuó, ya que la institución se fusionó con el recién fundado Instituto Alemán de Cultura/Deutsches Kulturinstitut, que tenía su sede en un palacio de la Avenida del Generalísimo número 35, hoy en día Paseo de la Castellana. En ella se ubicaría el núcleo de la sección madrileña del IAA.

Desde 1941, el Instituto Científico Alemán/Deutsches Wissenschaftsinstitut también había estado allí, asumiendo las tareas de los otros institutos existentes. Una sucursal funcionó en Barcelona. Estos Institutos Científicos fueron el resultado de la aplicación de las ideas procedentes de los nacionalsocialistas. Bajo el pretexto de la ciencia, perseguían intenciones concretas y tenían tareas precisas ${ }^{20}$. El instituto en Madrid asumió el tema de exposiciones. Sin embargo, la única exposición que se llegó a organizar fue en 1945 sobre "Artistas alemanes en la época de Durero. Exposición de reproducciones y fotografías" (8.4.-3.5.1941). Además, se organizaron numerosas conferencias sobre multitud de temas científicos. La institución fue cerrada al final de la guerra ${ }^{21}$.

Poco después del final de la Guerra Civil española, Martin Schede ${ }^{22}$, en ese momento Presidente del IAA, retomó el antiguo plan y escribió a su ministerio superior en Berlín solicitando la creación de un departamento del Instituto en España. Helmut Schlunk iba a actuar como director fundador, aunque no era miembro del partido ni estaba cerca de estos círculos. El interlocutor español en aquel entonces era Julio Martínez Santa-Olalla, como Comisario General de Excavaciones, quien en ese momento inició los trabajos científicos en Castiltierra para los que esperaba la participación alemana. Sin embargo, esto no ocurrió, al abstenerse la parte alemana de hacerlo sobre la base de un informe de Joachim

20 Hausmann, 2001.

21 Ibídem.

22 Brands y Maischberger, 2012. 
Werner ${ }^{23}$, quien había sido enviado a la península con este fin en 1941, ya que Werner aconsejó no fundar un departamento mientras Martínez Santa-Olalla estuviera en el cargo. Sin embargo, en el invierno de 1941 se tomaron las medidas necesarias. Así que Schede puso dinero a disposición y organizó un viaje a España de Schlunk, que era soldado en Francia. El pretexto fue la invitación a dar conferencias en el Centro de Estudios Históricos, que fue expresada oficialmente por Manuel Gómez-Moreno como presidente, Diego Angulo como director y Blas Taracena como secretario. En febrero de 1942, Schede informó al departamento cultural de su ministerio que Schlunk estaba listo para viajar, y en noviembre de 1942 se le concedió el permiso. El hecho de que la parte alemana actuara de acuerdo con la española queda demostrado por una comida que tuvo lugar el 15 de diciembre de 1942 en el restaurante Mariscal de Madrid (calle Peligros, número 4), al que Theodor Heinermann, Director del Instituto Científico Alemán/Deutsches Wissenschaftsinstitut había invitado al arqueólogo Antonio García y Bellido, catedrático de la Universidad de Madrid y miembro de la Real Academia de Historia. La fecha está demasiado cerca de la conclusión del Acuerdo Comercial Hispano-Alemán ${ }^{24}$ como para excluir una conexión. De esta manera se allanó el camino para que el 3 de marzo de 1943 se pudiera inaugurar la biblioteca de la sucursal madrileña del IAA.

Los numerosos intentos alemanes de abrir institutos de humanidades en España durante la primera mitad del siglo XX contrastan con Francia, que con su Escuela de Altos Estudios Hispánicos, fundada en 1909 y centrada en los estudios hispánicos, creó una institución que ha sobrevivido hasta nuestros días: la posterior Casa de Velázquez (1928). Los intentos anglosajones en este sentido fracasaron desde el principio (Fig. 1).

Figura 1. Fundación de institutos de investigación científica de humanidades en España

\section{Fundación de institutos científicos extranjeros de humanidades en España}

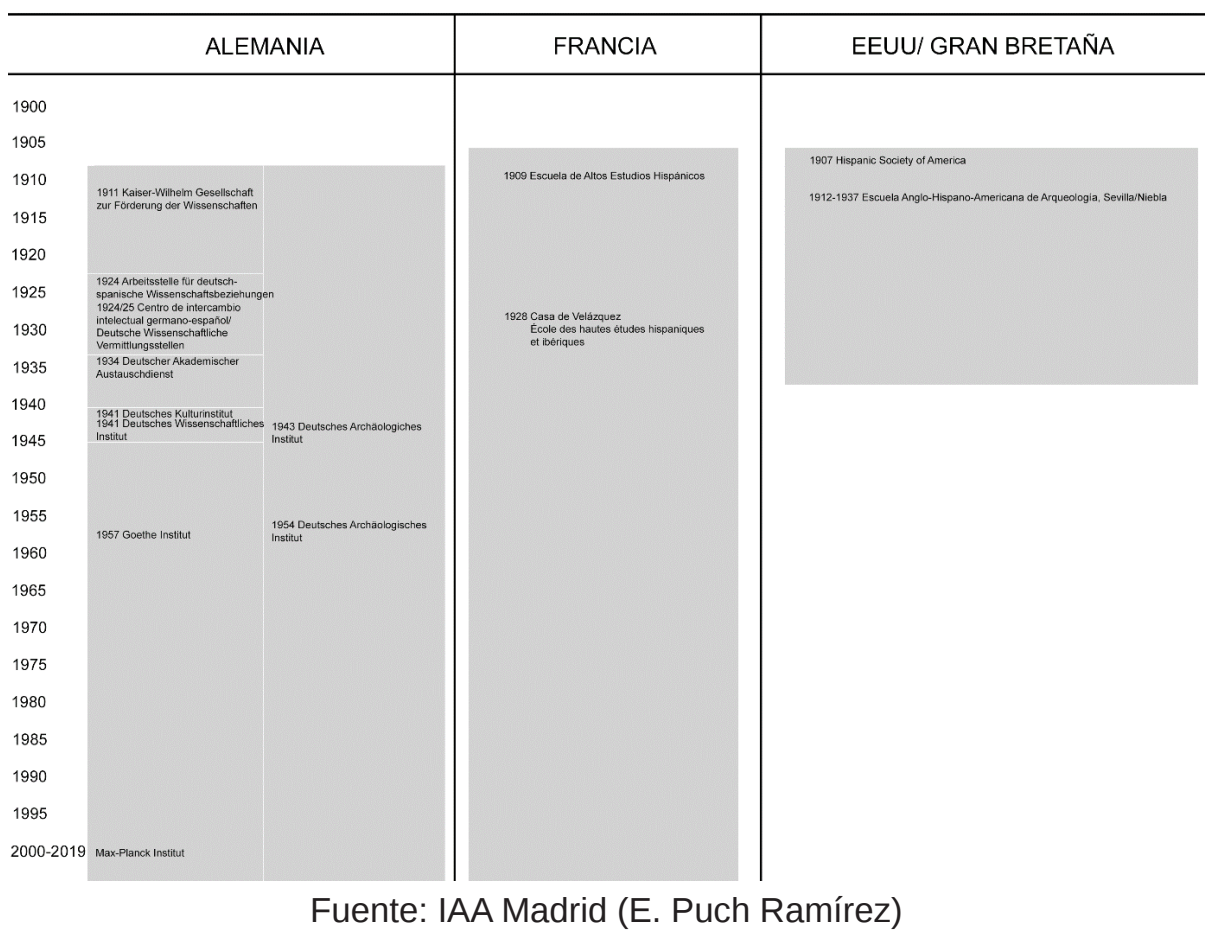

23 Maier y Schattner, 2013:333-345 (documento núm. 9).

24 Molina, 2013. 


\section{EL ARQUEÓLOGO COMO HISPANISTA}

Los arqueólogos a menudo desarrollan su propia relación íntima con la región, el país o los países en los que trabajan. Por un lado, esto puede tener algo que ver con su misma presencia, que suele ser larga — muchas veces de por vida—, en los países anfitriones; por otro lado, por supuesto, se basa en su ocupación profesional diaria centrada en los legados de las antiguas culturas de estos países y, por lo tanto, en una profunda penetración intelectual en la materia científica. La combinación de ambos conduce a una comprensión a menudo profunda no sólo de las culturas del Viejo Mundo, sino también de las peculiaridades de las condiciones de vida modernas, ya que en las excavaciones en el campo uno se encuentra con las situaciones más diversas en las que está implicada gente del entorno. La estructura específica del trabajo de investigación del Instituto Arqueológico Alemán y de sus departamentos en el extranjero promueve la comprensión de estas diversas condiciones. Por su estructura siempre ha sido multipolar con una visión de permanencia a largo plazo, de ahí que al menos algunos de sus investigadores tengan esa prolongada presencia antes mencionada en los países anfitriones.

El Instituto Arqueológico Alemán (IAA) es una de las instituciones de investigación más antiguas de Alemania. Su historia comenzó en Roma el 21 de abril de 1829, cuando un círculo de amigos formado por eruditos, artistas y diplomáticos de origen alemán, italiano, francés, inglés y otros, fundaron el "Instituto di corrispondenza archeologica". El objetivo de la fundación era tratar la Antigüedad no sólo sobre la base de los restos visibles en Roma, sino también sobre la base de los restos que se conservan en Italia y en la región mediterránea, y recoger y publicar los hallazgos arqueológicos. Los primeros años estuvieron marcados por el pensamiento europeo. El príncipe heredero y más tarde rey de Prusia Federico Guillermo IV asumió el protectorado del instituto. Grandes mentes de la ciencia, el arte y la cultura se convirtieron en miembros entusiastas. Goethe, Schinkel, Alexander von Humboldt y numerosos eruditos extranjeros formaron parte, así como varios soberanos de Europa y una gran parte de la aristocracia internacional desde París a San Petersburgo. El Instituto es, pues, una de las primeras expresiones de una identidad cultural europea común.

En 1833, los líderes se trasladaron de Roma a Berlín, donde la sede del Instituto ha permanecido hasta el día de hoy. En 1871 el Instituto se convirtió en el Instituto Estatal Prusiano y en 1874 en el Instituto Arqueológico del Reich. Bismarck se aseguró de que quedara bajo la jurisdicción del Ministerio de Asuntos Exteriores. Reconoció la importancia del Instituto y de la ciencia arqueológica para la política cultural exterior, para toda la cultura alemana y europea. En 1871 se fundó el departamento de Atenas, en 1902 la Comisión Romano-Germánica de Frankfurt, en 1929 los departamentos de Estambul y El Cairo, y en 1943 se colocó la primera piedra de la institución en Madrid, que ha estado trabajando continuamente desde 1954. Le siguieron el Departamento de Bagdad en 1955, Teherán en 1961 y la Comisión de Historia Antigua y Epigrafía de Munich en 1967. Las estaciones de Sanaa y Damasco se añadieron en 1978 y 1980. La Comisión de Arqueología de las Culturas No Europeas se inauguró en Bonn en 1979. En 1995, el IAA fundó el Departamento de Eurasia en Berlín, cuyos investigadores procedían en parte de la Academia de Ciencias

de la extinta RDA. Debido a la crisis, los departamentos en Bagdad, Damasco y Sanaa tuvieron que volver a Berlín, lo que también ocurrió con el departamento de Teherán por algún tiempo. En la última década se han vuelto a crear centros de investigación, en 2005 el Instituto Evangélico de Jerusalén y Aman, en 2007 en Ulaanbataar (Mongolia) y en 2009 en Beijing y Lisboa ${ }^{25}$. 
La relación íntima mencionada anteriormente se manifiesta de varias maneras. Siempre se caracteriza por el hecho de que además de la observación científica sobria, hay otra que está guiada por impresiones y emociones personales. Carl Humann (1839-1996), el excavador de Pérgamo, que vivió en Turquía desde 1861 hasta su muerte en 1896, dejó sus memorias e impresiones, como muchos otros, en un libro ${ }^{26}$. Esto también se aplica a Kurt Bittel (1907-1991), el excavador de la capital hitita Hattusha y más tarde presidente del IAA que no sólo trabajó y vivió en Asia Menor, sino que también investigó en Egipto, Bulgaria y Grecia ${ }^{27}$. Theodor Wiegand (1864-1936), el excavador de Mileto y Didyma, escribió un delicado volumen sobre el paisaje alrededor de Mileto como preludio a la publicación de Mileto ${ }^{28}$, él también ha mantenido vivos sus recuerdos de la vieja Turquía ${ }^{29}$. Klaus Tuchelt, más tarde el gran excavador de Didyma, dedicó su trabajo no sólo a las antigüedades de Turquía, sino también a las casas de madera del siglo XVIII en el Bósforo como testimonios del antiguo Estambul ${ }^{30}$. Además de las impresiones personales, las descripciones ofrecen una imagen vívida de los países de cada época. Los libros arrojan luz sobre sus autores, que no se contentaron con describir los monumentos arqueológicos, sino que, mucho más allá, centraron su atención en la gente, su entorno y sus condiciones de vida y, de este modo, retrataron el país en sus facetas más entrañables. En la "Milesische Landschaft" de Wiegand, el tema dominante es la naturaleza.

Figura 2. Emil Hübner (1834-1901)

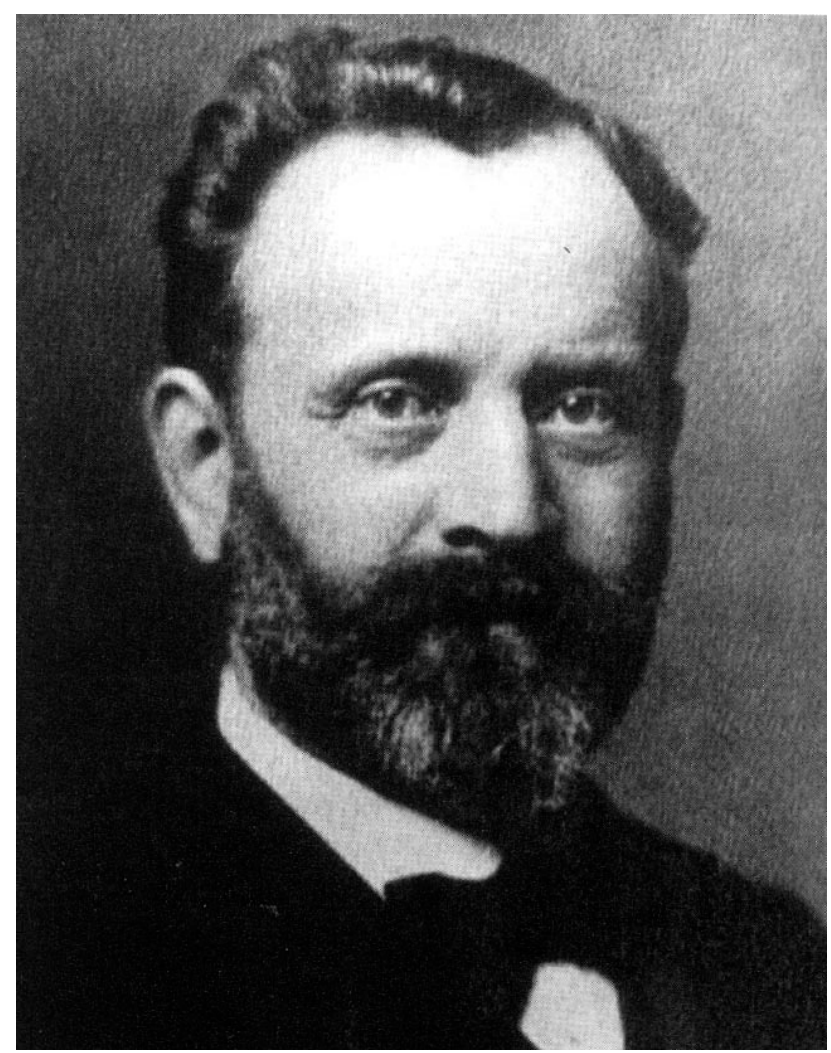

Fuente: IAA Madrid

26 Reisen in Kleinasien und Nordsyrien (Berlin 1890).

27 Reisen und Ausgrabungen in Ägypten, Kleinasien, Bulgarien und Griechenland 1930-1934 (Wiesbaden 1998). 28 Die milesische Landschaft, Milet. Ergebnisse der Ausgrabungen und Untersuchungen seit dem Jahre 1899, vol. 2,2, Berlin.

29 Wiegand, 1970.

30 Tuchelt 1962. 
En España, el epigrafista berlinés Emil Hübner (1834-1901) es la personalidad investigadora más importante de la segunda mitad del siglo XIX (fig. 2). Fue el "hombre de viajes" (Reisemann) de Theodor Mommsen para la Península Ibérica con la tarea de crear el corpus de inscripciones latinas (Corpus Inscriptionum Latinarum). A partir de su llegada a Madrid en 1861, y en colaboración con sus colegas españoles de la Real Academia de la Historia, Aureliano Fernández-Guerra, Fidel Fita, Eduardo Saavedra, José Ramón Mélida y Manuel Gómez-Moreno, pudo inmediatamente no sólo abordar la tarea científica de forma extremadamente eficaz, sino también establecer una relación amistosa con las personas antes mencionadas sobre la base de su cosmopolitismo y destreza, su apariencia y su autoconfianza. El éxito de la empresa consistió en una planificación perfecta. Inicialmente todavía sin ferrocarril, recorrió el país en carroza, caballo y burro, buscando siempre las transcripciones y las ediciones de las inscripciones que había encontrado en los archivos de la Academia. La Academia fue el punto de recolección de los hallazgos arqueológicos establecidos por Carlos III. De esta manera, Hübner recogió, leyó, reescribió y editó más de 6.300 inscripciones. Además, su impresionante y extensa bibliografía también incluye trabajos sobre historia antigua, filología, arqueología clásica y provincial. A parte, realizó un catálogo de las esculturas antiguas y relieves que encontró en sus primeros viajes. La publicación tuvo lugar de forma inmediata en el año 1862 ${ }^{31}$. En 1887 Hübner recibió un premio "Accésit" en el I Premio Martorell por su obra "La arqueología de España", en la que recopiló los monumentos más importantes y los describió con la intención de ofrecer una especie de manual a los interesados. Fue colmado de honores, todos ellos procedentes de España y Portugal. En la propia Alemania no se percibía la luz radiante que emanaba, se le consideraba un hispanista, que había tratado con temas de la Antigüedad hispánica en su conjunto, similar a Adolf Schulten (1870-1960) una generación más tarde ${ }^{32}$.

Schulten era una personalidad controvertida (fig. 3) ${ }^{33}$. Mientras que Hübner había logrado liberarse de los prejuicios de su época y llegar a una presentación objetiva de los hallazgos y circunstancias, Schulten, con sus diversos estudios, permaneció apegado al espíritu del período Wilhelminiano y en ello fiel a su época. Siempre fue un hijo de ese tiempo, creyendo en los rasgos de carácter constante de los pueblos. Tenía una profunda formación en las lenguas de la Antigüedad, especialmente en latín, conocía las fuentes escritas antiguas hasta el último detalle y se le podía considerar por eso mucho más preparado que sus colegas españoles, que, sin embargo, le eran leales, entre otras cosas porque sobre esta base trazó una historia prerromana de Hispania, en la que este país desempeñó un papel destacado a la cabeza del mundo civilizado. De una manera peculiar, había vinculado su propio significado como historiador de la Antigüedad con el de la antigua Hispania, de modo que el magnífico resplandor de esta, también se le pegó a él como su intérprete. Su profundo positivismo se desencadenó en vuelos de fantasía, a los que su imaginación romántica le dio alas.

Dos descubrimientos fueron importantes: Numancia, que descubrió con Appiano en la mano, y Tartessos/Tarschisch, que pensó haber encontrado a partir de la obra de Avieno. De esta manera, la "Ora Maritima" jugó un papel similar al de "La llíada" de Homero. Schulten llegó a España por primera vez en el invierno de 1901-1902 con la intención de encontrar Numancia, descrita en detalle por Appiano, propósito que logró en el verano de 1902 al estar bien documentado por las informaciones de Eduardo Saavedra, ingeniero y arqueólogo

31 Maier y Schattner, 2008.

32 Marzoli, Maier y Schattner, 2014.

33 P. ej. Wulff, 2004. 
Figura 3. Adolf Schulten (1870-1960)

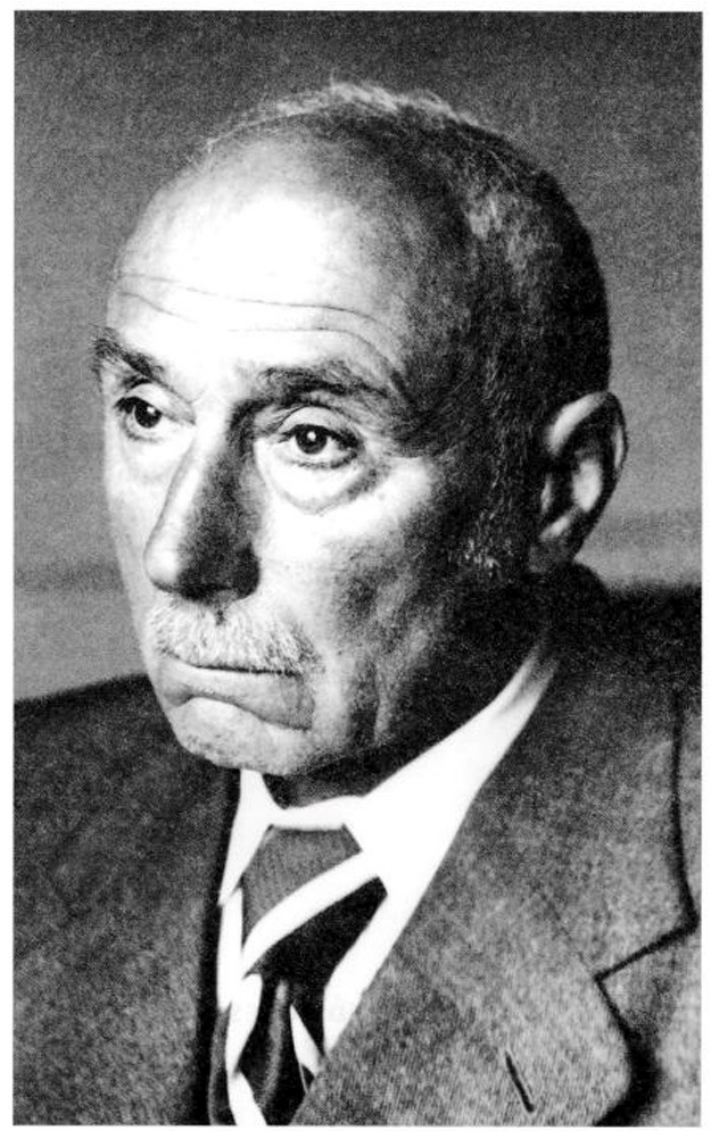

Fuente: IAA Madrid

aficionado, que ya había identificado el lugar 40 años antes. Sin embargo, el descubrimiento le ayudó a dar un salto en su carrera, ya que consiguió pasar de profesor asistente a profesor catedrático en la Universidad de Erlangen en 1907, donde enseñó hasta su jubilación ${ }^{34}$. Su "Viriathus" (1917) es particularmente característico, ya que ilustra su forma de trabajar. Aquí la firmeza y la incontrolabilidad salvaje de los hispanos se yuxtaponen con la deslealtad y la astucia de los romanos. Esta materia, junto con la dimensión guerrera e histórica del conflicto numantino, la utilizó para desarrollar una historia española nacionalista del período romano, que España adoptó y hasta divulgó después de 1936, lo que no dejó de tener influencia decisiva en la imagen de España ofrecida en los libros escolares. En su argumento, Schulten establece una tensión argumentativa - y en el fondo no resoluble- que en ambos casos, tanto en el de Numancia como en el de Viriato, un pueblo culturalmente más desarrollado como el romano, derrota a otro menos desarrollado como el hispano, cuando el hispano, sin embargo, preservó su carácter tradicional, su "carácter de pueblo", en una medida mucho mayor.

Sin embargo, los méritos científicos de Schulten no dejan de ser importantes incluso a nivel internacional, sobre todo en ese momento, en el que los extranjeros desempeñaron un papel importante en la investigación de la historia antigua en España: los hermanos belgas Henri y Louis Siret, que dieron un nuevo impulso a la Edad de Bronce del Sureste con sus espectaculares hallazgos, Archer Huntington, el hispanista estadounidense, coleccionista de arte y promotor de la ciencia que fundó la "Hispanic Society of America", el epigrafista alemán Emil Hübner, el estudioso francés Pierre Paris, la inglesa Elena Whishaw, que llegó 
a Andalucía con su marido en 1910 y se instaló en Niebla en 1915, donde dirigió la "Escuela Angloamericana de Arqueología". La época está, además, marcada por la introducción de nuevos y sistemáticos métodos de excavación. A pesar de todo, Schulten logró convertirse en el patriarca de las Ciencias de la Antigüedad españolas. Solo recientemente, durante la última generación la investigación historiográfica ha conseguido asignarle el lugar que se merece de acuerdo con sus logros.

Hugo Obermaier (1877-1946) es una de las grandes personalidades de la prehistoria hispánica de la primera mitad del siglo XX (fig. 4) ${ }^{35}$. A través de su disciplina científica, su investigación, su trabajo de campo y sus publicaciones, pero también a través de su docencia y su talento organizativo práctico, ha tenido una profunda influencia en la investigación en España ${ }^{36}$. Transmitió una tradición de investigación alemana y su papel no se limita a ser uno de los pioneros de la creación de un departamento del Instituto Arqueológico Alemán en Madrid. Como clérigo católico, no sólo estudió teología, sino también geología, filología antigua, etnología, anatomía y filología alemana. Era bastante introvertido, pero al mismo tiempo enérgico y directo $y$, en vista de su fe, un hombre de convicciones firmes. Durante su visita de estudio a París en 1904-1905, conoció al abate francés Breuil, con quien tuvo una amistad de por vida. La vinculación se extendió a viajes, investigaciones y publicaciones en común. Como secretarios del "I Congrès International d'Anthropologie et d'Archéologie Préhistorique" de Mónaco en 1902, tuvieron ocasión de entrar en contacto con el príncipe Alberto I, que se entusiasmó con ellos y se convirtió en su mecenas. Este también fue miembro de la expedición de 1909 a las cuevas de Cantabria, cuando Obermaier llegó a España por primera vez.

Figura 4. Hugo Obermaier (1877-1946)

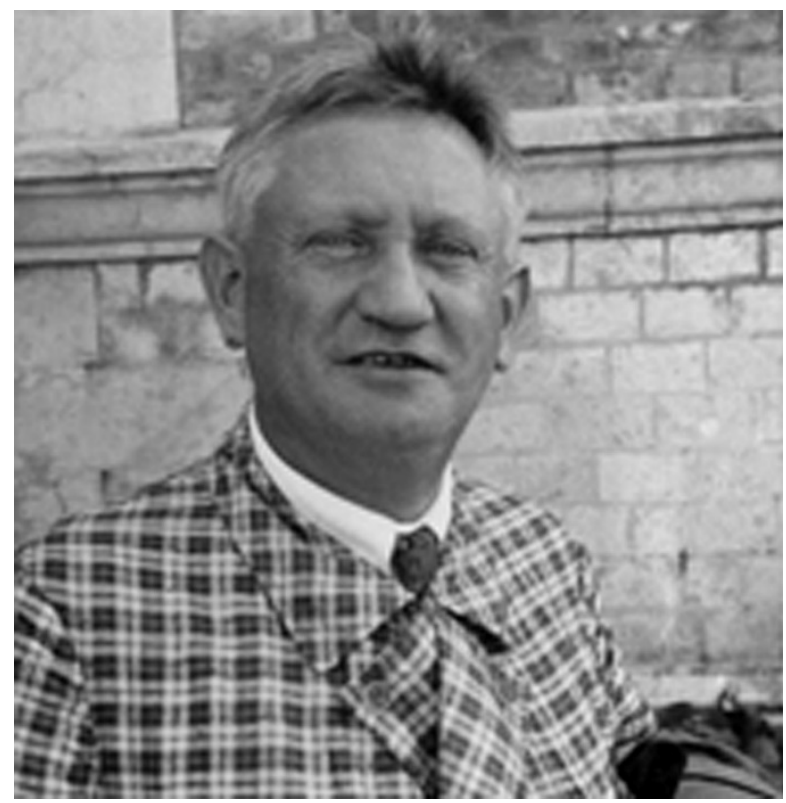

Fuente: IAA Madrid

La importancia de Obermaier para la arqueología española radica sobre todo en el hecho de que aportó un soplo de aire fresco al paisaje de investigación español, que se encontraba un tanto estancado ante la situación política de la Guerra de Cuba de 1898 y, 
por lo tanto, la perdida de las últimas colonias españolas y su remisión a la independencia. Así, la investigación se encontraba en crisis y en una situación de aislamiento. Pero con Obermaier y Breuil, la investigación prehistórica española reabrió sus puertas a Europa. Así, ante el trasfondo de las corrientes generales, especialmente pero también como consecuencia de la restauración borbónica, se observa la promulgación de la "Ley de Excavaciones Arqueológicas" de 1911, que dio lugar a la creación de la "Junta Superior de Excavaciones y Antigüedades" en el año 1914, la célula germinal de la creación del patrimonio de los monumentos históricos españoles. Paralelamente, se constituyó la "Junta de Ampliación de Estudios", que permitió a los becarios españoles realizar estancias en el extranjero a través de becas. También fue durante este periodo cuando se fundaron la "Escuela Española de Historia y Arqueología en Roma" (1910) y la "Comisión de Investigaciones Paleontológicas y Prehistóricas" para promover los estudios prehistóricos. Es la época de hombres como Joaquín Costa (1846-1911), como representantes de la Generación del 98 y del Regeneracionismo, del jesuita y epigrafista Fidel Fita Colomé (1835-1918), de los celtistas franceses Marie Henri d'Arbois de Jubainville (1827-1910) y Joseph Déchelette (1862-1914), así como del Marqués de Cerralbo (1845-1922) en calidad de mecenas e investigador. Tras ser acusado por los alemanes de su amistad con Breuil, que defendió públicamente y tras verse obligado a abandonar Francia (como alemán) como consecuencia de los actos de guerra de la Primera Guerra Mundial, Obermaier se dirigió a España. En Madrid, en 1916, recibió inmediatamente una cátedra en el Museo de Ciencias Naturales, que ocupó hasta 1919. En esta época se publicó su famosa obra "El hombre fósil", en la que combinaba brillantemente los hallazgos geológicos y científicos en una síntesis con la investigación paleontológica. Representa, en su esencia, su logro científico, que obtuvo junto con Breuil y Teilhard de Chardin. Tiene el mérito de haberse acercado a la solución de la cuestión del origen del hombre en el conflicto entre el conocimiento científico y la investigación bíblica. El trabajo se publicó por primera vez en España y en lengua española y de esta manera hizo que el mundo intelectual, que ya había tomado conciencia de España a través de la investigación extranjera antes mencionada, se familiarizara también con el español como lengua de la ciencia. Obermaier se veía a sí mismo como un mediador entre estos dos mundos, el alemán y el español. Por lo tanto, su compromiso como editor de la ya descrita revista "Investigación y Progreso" es evidente. Obermaier encajó bien en Madrid. Entre sus contactos cabe mencionar, en primer lugar, al Duque de Alba, director de la Real Academia de la Historia ${ }^{37}$, del que se convirtió en capellán personal y que financió la impresión de sus obras, quien le introdujo en el mundo académico español, por lo que no es de extrañar que recibiera la cátedra de Historia Primitiva del Hombre en la Universidad de Madrid en 1922. La lista de sus alumnos es larga. Son ellos, de los que proviene la siguiente generación de prehistoriadores en el país. El estallido de la Guerra Civil Española le sorprendió en Oslo, donde participó como representante de España en el "Il Congreso Internacional de Arqueología Prehistórica y Protohistórica". En vista de la situación permaneció en el extranjero y no regresó a España, sino que se hizo cargo de la cátedra vacante en la Universidad Católica de Friburgo (Suiza) en 1938, donde murió ${ }^{38}$.

Helmut Schlunk (1906-1982) ocupa un lugar especial entre todos los arqueólogos mencionados en este ensayo (fig. 5). Por un lado, porque dedicó el trabajo de investigación de toda su vida exclusivamente a temas de la Península Ibérica y, por otro, porque fue director fundador del Departamento de Madrid del Instituto y en esta función no sólo obtuvo

37 Sobre la actuación de esta institución véase p. ej. Tortosa y Mora, 1996.

38 Maier y Schattner, 2013. 
Figura 5. Helmut Schlunk (1906-1982)

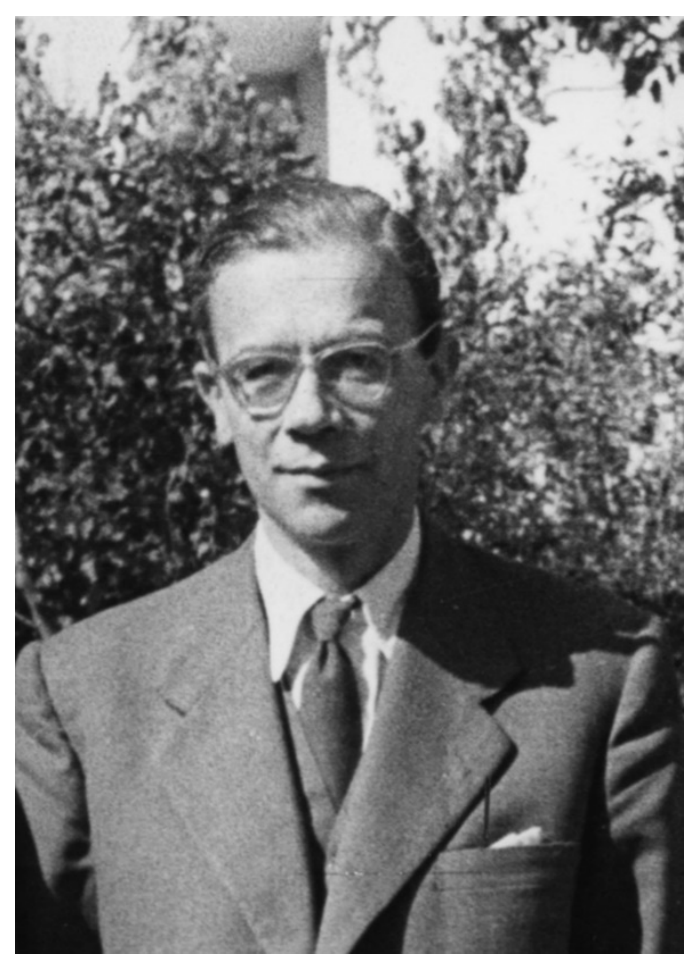

Fuente: IAA Madrid

méritos inestimables, sino que le dio un marco científico y humano a esta casa con su especial forma de ser, de una manera que aún hoy constituye el espíritu de la casa, sobre todo porque ha sido mantenido por todos sus sucesores: Wilhelm Grünhagen, Hermanfrid Schubart, Thilo Ulbert y, en la actualidad, Dirce Marzoli y sus correspondientes equipos. De esta forma, su trayectoria puede servir de ejemplo.

Se contó para la divulgación de ese espíritu con la contribución del edificio mismo, que no es nada desdeñable. Es una casa de los años treinta situada en la calle Serrano 159, a la que el Instituto de Madrid se trasladó en 1953, que ha conservado su esencia a lo largo de todo este tiempo. El parquet del salón y el suelo de baldosas de la habitación, en la que estaba el antiguo aparador forman parte de la casa, al igual que las estanterías de los libros con su olor característico, las mesas y sillas antiguas, la vista desde la ventana hacia el pequeño jardín delantero. Los lectores se sienten como en casa.

Schlunk llegó a España en 1928-1929 en el curso de su tesis doctoral sobre ornamentación arquitectónica visigoda. En ese momento, esa disciplina académica estaba encuadrada en el área de la Antigüedad Tardía en las universidades. A raíz de las investigaciones de Alois Riegl en Viena, había experimentado una nueva orientación positivista en ese momento. En este contexto, la ornamentación en particular adquirió un nuevo papel como rasgo distintivo de las diferentes culturas, ya que se consideró una expresión de la voluntad artística respectiva. La tesis de Schlunk tenía por objeto rastrear las raíces de la ornamentación y su desarrollo desde el periodo visigodo hasta el siglo $\mathrm{X}$, incluyendo influencias de Oriente y Occidente. Sólo Gómez-Moreno había investigado sobre este tema por parte española. En este sentido, Schlunk abrió nuevos caminos y sentó las bases para futuras investigaciones. También en España, desde la aparición de la famosa obra de Gómez-Moreno sobre las iglesias mozárabes (1919) había comenzado un nuevo interés por el arte y la arquitectura visigoda. Como recién doctorado, Schlunk volvió a España en 1932 por dos años, esta vez con una beca de la Academia de Ciencias 
de Berlín. Su tarea consistía en la documentación de varias construcciones notables de la Antigüedad, junto con el arquitecto Harald Hanson. Esto implicaba viajes y de esta manera Schlunk conoció a las personalidades más importantes de aquel entonces de la investigación sobre la Antigüedad española: Félix Hernández en Córdoba, Antonio García y Bellido, Emilio Camps Cazorla, Luís Vázquez de Parga y sobre todo Manuel Gómez-Moreno en Madrid, Leopoldo Torres Balbás en Granada y Diego Angulo Iñiguez en Sevilla. A continuación, Schlunk obtuvo otra beca en los EE.UU. de 1933 a 1935, residiendo —entre otros sitios-en Princeton. Cuando fue nombrado conservador de arqueología paleocristiana y bizantina en el Museo Kaiser Friedrich de Berlín, le resultó difícil regresar a Alemania por razones políticas.

Su experiencia en España, sin embargo, lo hizo interesante para el Instituto Arqueológico Alemán, que estaba planeando establecer un departamento en Madrid en ese momento, como se describió anteriormente. Como director fundador, se trasladó a Madrid en 1943. Al final de la guerra y con el cierre del Instituto de Madrid, se refugió en España. De no ser por becas e invitaciones a conferencias en universidades, que los compañeros españoles le facilitaban, no hubiera podido sobrevivir. Cabe destacar especialmente a Gómez-Moreno y García y Bellido, que lo aceptaron en el círculo familiar. En los años 1949 y 1952 sus colegas le concedieron de nuevo becas en Londres y en Dumbarton en los Estados Unidos. Finalmente, cuando el IAA reabrió sus puertas en 1954 pudo reanudar su trabajo y continuar en la institución hasta su jubilación en 1971. Después de la reapertura la atención se centró principalmente en la rápida puesta en marcha de proyectos para el instituto. Así, emprendió varios viajes por el país con el fin de sondear posibles proyectos con sus colaboradores, que en su mayoría fueron propuestos como adecuados por la parte española o portuguesa (Fig. 6). Finalmente, la decisión se tomó a favor de Centcelles/Tarragona y Munigua/Sevilla, en el primer caso una villa tardorromana con una importante cúpula de mosaico (Fig. 7), y en el segundo una ciudad hispano-romana con edificios extraordinarios (Fig. 8).

Figura 6. Viajes de Schlunk y sus colaboradores en la Península en busca de proyectos

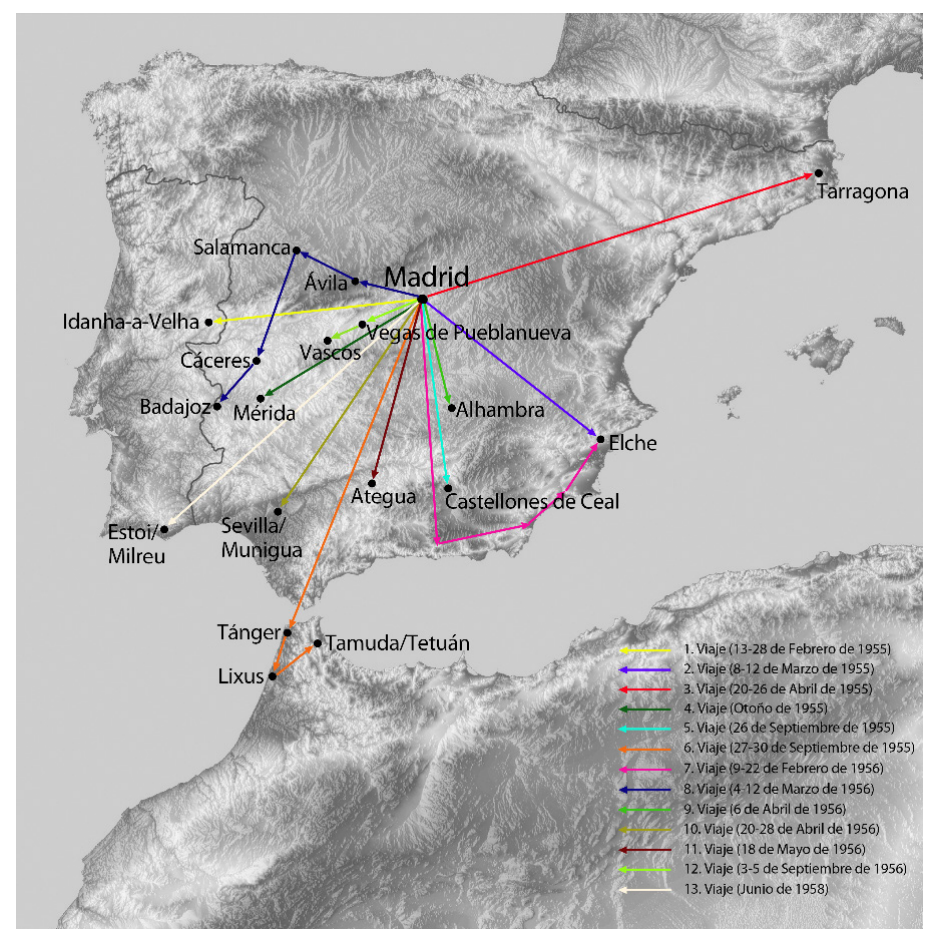

Fuente: IAA Madrid (E. Puch Ramírez) 
Figura 7. La granja de Centcelles en 1958

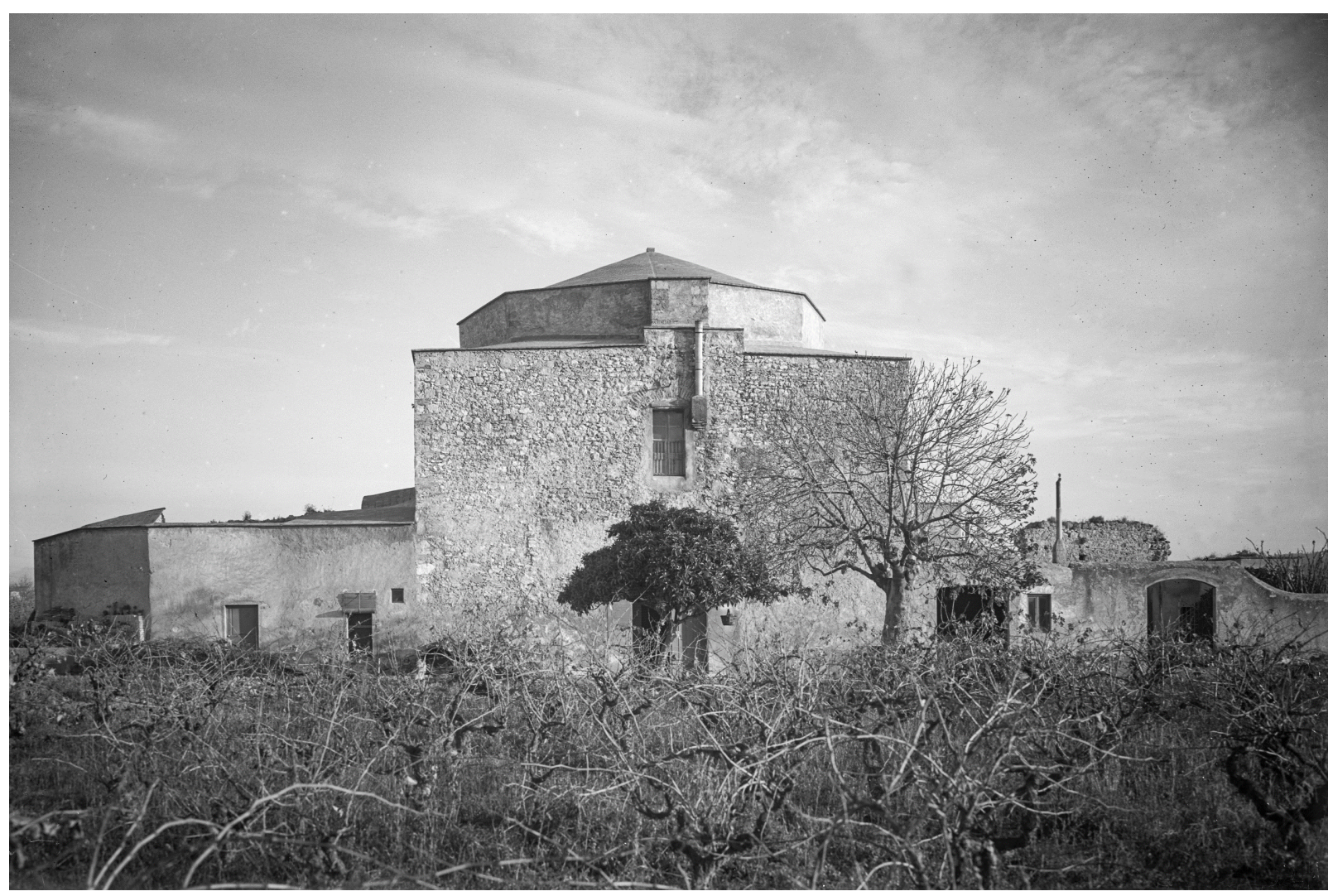

Fuente: D-DAI-MAD-SCH-1489

Figura 8. Vista sobre las excavaciones en Munigua hacia el año 1959

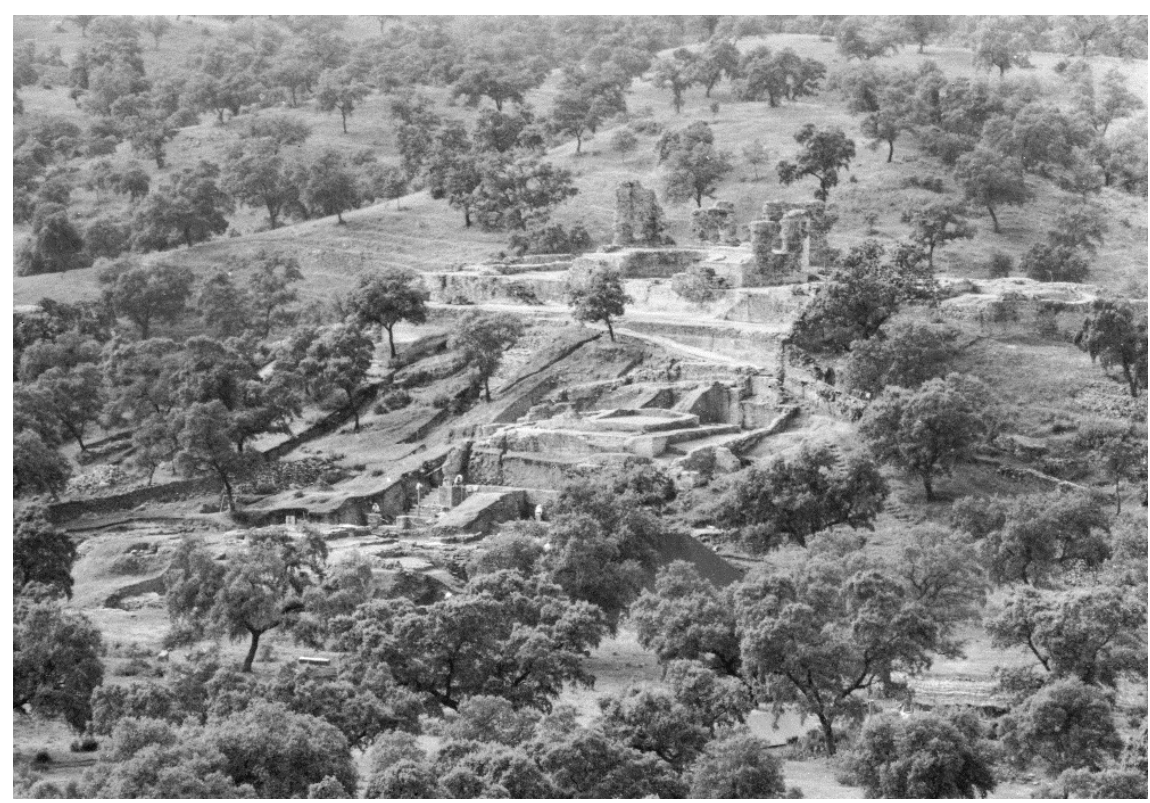

Fuente: D-DAI-MAD-un-KB-A-889-06

Desde el comienzo, el carácter cooperativo de todas las empresas fue el centro de atención. Al mismo tiempo, muchos de los monumentos del país, desde la Prehistoria hasta la Edad Media, fueron documentados y plasmados en fotografías y dibujos en muchas campañas. Los archivos correspondientes del IAA contienen hoy más de 100.000 imágenes 
y 78.000 dibujos. Tuvieron su reflejo en la publicación de carácter generalista de cinco volúmenes "Hispania Antiqua". También se iniciaron las publicaciones de la casa, así como su revista "Madrider Mitteilungen" y las series monográficas "Madrider Forschungen" y "Madrider Beiträge". De forma bastante inusual para el IAA, se ha creado un puesto para un investigador de la Arqueología de la Construcción (Bauforschung), que se ocupa del arte y la arquitectura islámica, lo que ha permitido extender la investigación a Marruecos. En 1971 se fundó una sucursal en Lisboa, pero tuvo que ser cerrada de nuevo en 1999 por razones de coste. Desde 2009 ha sido sustituido por un punto de investigación. Sin el talento de Schlunk para la organización, su creatividad, su curiosidad científica y su inquietud, el departamento no podría haber sido fundado. El apoyo que prestó a científicos especialmente jóvenes y su interés en su trabajo, han hecho de él una personalidad inolvidable. Sin la amabilidad de sus colegas y amigos españoles, portugueses y marroquíes, sin embargo, los científicos del IAA Madrid no habrían nunca podido realizar su trabajo. La base era una relación amistosa y de confianza, que solo ha podido darse de esta manera porque se vive en el propio país, se celebran y sufren sus altibajos, por lo tanto, finalmente se establece una profunda relación de amistad con todos ellos.

\section{CONCLUSIÓN}

A modo de conclusión constatamos el creciente interés mutuo entre Alemania y España a lo largo de los siglos. Este comienza a intensificarse desde la segunda mitad del siglo XVIII a través de la literatura de viajes a través de la cual tanto España como Italia se convirtieron en un lugar europeo de anhelo. El hispanismo es, en esa época, una hispanofilia vista desde lejos. Hacia 1830, se puede observar el descubrimiento cultural, artístico, literatura y pictórico de Andalucía, que en la época romántica pasa a ser la encarnación de España. Como resultado, surgió en España la tendencia literaria del costumbrismo. El período coincide con las primeras investigaciones científicas a mayor escala. Son testimonio los hermanos von Humboldt, Wilhelm con su investigación lingüística sobre el euskera, y Alejandro con su viaje geodésico que culminaba con la escalada al Pico del Teide como preparación para sus expediciones a Sudamérica. Además, hay que mencionar también a los botánicos Heinrich Friedrich Link y Johann Centurius von Hoffmannsegg. El hispanismo gana otra dimensión en ese momento al ser una sensación vivida por los visitantes en su propia piel. Hacia el final del siglo XIX España correspondió a este interés con la primera "Historia general de Alemania" en tres volúmenes de Vicente Ortiz de la Puebla (1877), al igual que un "Ensayo sobre el movimiento intelectual en Alemania" de José del Perojo y Figueras (1875), traductor de La crítica de la razón pura de Kant. A principios del siglo XX con la creación de la Institución Libre de Enseñanza, con la Residencia de Estudiantes y la Junta de Ampliación de Estudios e Investigaciones Científicas (1907), Alemania y sus instituciones pasan a ser el modelo a seguir. Antes de la Primera Guerra Mundial, casi la mitad de los becarios fueron a Alemania. Con el establecimiento de instituciones científicas alemanas de Humanidades en España en el período de entreguerras, el hispanismo evoluciona. Ahora, los científicos alemanes residen de forma permanente en el país, conviven codo con codo con los españoles, lo que facilita y proporciona el intercambio, la colaboración y la amistad. El Instituto Arqueológico Alemán de Madrid y su historia es el mejor ejemplo.

\section{BIBLIOGRAFÍA}

Bader, W. y Olmos, I. (2004): Die deutsch-spanischen Kulturbeziehungen im europäischen Kontext: Bestandsaufnahme, Probleme, Perspektiven, Frankfurt, Vervuert.

Brands, G. y Maischberger, M. (2012): Lebensbilder. Klassische Archäologen und der Nationalsozialismus, Menschen-Kulturen-Traditionen, Studien aus den 
Forschungsclustern des Deutschen Archäologischen Instituts, vol. 2,1, Rahden, Verlag Marie Leidorf.

Briesemeister, D. (2004): Spanienaus deutscherSicht. Deutsch-spanische Kulturbeziehungen gestern und heute, Tubingia, Max Niemeyer.

Díaz Andreu, M. (1995): "Arqueólogos españoles en Alemania en el primer tercio del siglo XX: Ios becarios de la Junta de Ampliación de Estudios: Bosch Gimpera", Madrider Mitteilungen, 36, pp. 79-89.

Geisler, E. (2001): España y Alemania: interrelaciones Literarias, Madrid, Iberoamericana Editorial Vervuert.

Giese, F. y Varela, A. (2016): The myth of the Orient: architecture and ornament in the age of orientalism, Berna, Peter Lang AG.

Giese, F., el-Wakil, L. y Varela, A. (2019): Der Orient in der Schweiz. Neo-islamische Architektur und Interieurs des 19. und 20. Jahrhunderts, Welten des Islams - Worlds of Islam - Mondes de I'Islam, vol. 10, Berlin, De Gruyter.

Hausmann, F-R. (2001): Auch im Krieg schweigen die Musen nicht. Die Deutschen Wissenschaftlichen Institute im Zweiten Weltkrieg, Gotingia, Vanderhoeck \& Ruprecht.

Hellwig, K. (2007): España y Alemania, intercambio cultural en el siglo XIX, Madrid, Iberoamericana Editorial Vervuert.

Hera Martínez, J. de la (2002): La política cultural de Alemania en España en el período de entreguerras, Madrid, CSIC.

Karge, H. y Fritz, W. (2007): Andalusien, Munich, Hirmer.

Maier, J. y Schattner, Th. G. (2008): "Presentación”, en Die antiken Bildwerke in Madrid [Las colecciones de arte antiguo en Madrid], Madrid, IAA.

- (2010): El Instituto Arqueológico Alemán y la arqueología de la Península Ibérica, en Rebok, S. (ed.): Traspasar fronteras: un siglo de intercambio científico entre España y Alemania [über Grenzen hinaus. Ein Jahrhundert deutsch-spanische Wissenschaftsbeziehungen], Madrid, CSIC y DAAD.

- (2013): Historia del Instituto Arqueológico Alemán de Madrid. . Antecedentes y fundación del Departamento de Madrid [Geschichte der Madrider Abteilung des Deutschen Archäologischen Instituts. Faszikel 1]. Iberia archaeologica, vol. 14, Darmstadt, Philipp von Zabern.

Margit Raders, M. y Schilling, M. L. (1995): Der deutsche und der spanische Schelmenroman, Madrid, Ediciones del Orto.

Marzoli, D., Maier, J. Y Schattner, Th. G. (2014): Geschichte der Madrider Abteilung des Deutschen Archäologischen Instituts. Faszikel 4. Emil Hübner und die Altertumswissenschaften in Hispanien, Akten des Kolloquiums in Madrid vom 19. bis 20. November 2008 zu Ehren des 175. Geburtstages von Emil Hübner [Historia del Instituto Arqueológico Alemán de Madrid. Fascículo 4. Emil Hübner y las ciencias de la antigüedad clásica en Hispania, Actas del coloquio celebrado en Madrid del 19 al 20 de noviembre del 2008 por el 175 aniversario del nacimiento de Emil Hübner], Iberia archaeologica, vol. 14, Darmstadt, Philipp von Zabern.

Marzoli, D., Schattner, Th. G. y Arnold, F. (2018): Die Abteilung Madrid des Deutschen Archäologischen Instituts: aktuelle Forschungen und Perspektiven, Madrid, IAA.

Molina, L. (2013): "El Convenio comercial hispano-alemán de diciembre de 1942. La antesala de la entrega masiva de armamento a España en la Segunda Guerra Mundial", Aportes, Revista de historia contemporánea, vol. 28 núm. 82, pp. 81-100.

Moure, A. (1996): El „hombre fósil“ 80 años después: volumen conmemorativo del 50 aniversario de la muerte de Hugo Obermaier, Gijón, Universidad de Cantabria.

Renner, R. G. y Siguán, M. (1999): Selbstbild und Fremdbild: Aspekte wechselseitiger 
Perzeption in der Literatur Deutschlands und Spaniens, Madrid, Forum 1 - Idiomas.

Rodiek, Ch. (2002): Dresden und Spanien. Akten des interdisziplinären Kolloquiums Dresden, 22.-23. Juni 1998, Frankfurt am Main, Vervuert.

Salas, J. de y Briesemeister, D. (2000): Las influencias de las culturas académicas alemana y española desde 1898 hasta 1936, Frankfurt am Main, Iberoamericana Editorial Vervuert.

Tietz, M. (1989): Das Spanieninteresse im deutschen Sprachraum: Beiträge zur Geschichte der Hispanistik vor 1900, Frankurt am Main, Vervuert.

Tortosa, M. T y Mora, G. (1996): "La actuación de la Real Academia de la Historia sobre el patrimonio arqueológico: ruinas y antigüedades", Archivo español de arqueología, 69, pp. 191-217.

Tuchelt, K. (1962): "Das Yalı des Kıbrıslı Mustafa Paşa in Kücüksu (Kandilli)", Istanbuler Mitteilungen, 12, pp. 129-158.

Vega, M. A. y Wegener, H. (2002): España y Alemania. Percepciones mutuas de cinco siglos de historia, Madrid, Editorial Complutense.

Vossler, K. (1944): Algunos caracteres de la cultura española. Traducido del alemán por Carlos Clavería, Barcelona, Austral.

Wiegand, G. (1970): Halbmond im letzten Viertel. Briefe und Reiseberichte aus der alten Türkei von Theodor und Marie Wiegand 1895 bis 1918, Munich, F. Bruckmann.

Wulff, F. (2004), Adolf Schulten. Historia antigua, arqueología y racismo en medio siglo de historia europea, en: Schulten, A: Historia de Numancia, IX-CCVII, Pamplona, Urgoiti. 